\title{
Does the Current State of Evidence Justify the Broad Use of Cross-Links in Dorsal Instrumentation? A Systematic Review
}

\author{
Vincent J. Heck ${ }^{1, *}{ }^{\oplus}$, Stavros Oikonomidis ${ }^{1} \oplus$, Tobias Prasse ${ }^{1}$, Carolin Meyer ${ }^{2} \oplus$, Max J. Scheyerer ${ }^{1}$, \\ Wolfgang A. Wetsch ${ }^{3}{ }^{-0}$, Peer Eysel ${ }^{1}$ and Jan Bredow ${ }^{1, *}$
}

1 Department of Orthopedics and Trauma Surgery, Faculty of Medicine and University Hospital Cologne, University of Cologne, Kerpener Str. 62, 50937 Cologne, Germany; stavros.oikonomidis@uk-koeln.de (S.O.); tobias.prasse@uk-koeln.de (T.P.); max.scheyerer@uk-koeln.de (M.J.S.); peer.eysel@uk-koeln.de (P.E.)

2 Center for Spinal Surgery, Schön Klinik Düsseldorf, Am Heerdter Krankenhaus 2, 40549 Düsseldorf, Germany; caromeyerkoeln@gmail.com

3 Department of Anaesthesiology and Intensive Care Medicine, Faculty of Medicine and University Hospital Cologne, University of Cologne, Kerpener Str. 62, 50937 Cologne, Germany; wolfgang.wetsch@uk-koeln.de

* Correspondence: vincent.heck@uk-koeln.de (V.J.H.); jan.bredow@uk-koeln.de (J.B.)

check for

updates

Citation: Heck, V.J.; Oikonomidis, S.; Prasse, T.; Meyer, C.; Scheyerer, M.J.; Wetsch, W.A.; Eysel, P.; Bredow, J. Does the Current State of Evidence Justify the Broad Use of Cross-Links in Dorsal Instrumentation? A Systematic Review. BioMed 2021, 1 , 1-10. https://doi.org/10.3390/ biomed1010001

Academic Editor: George Alexiou

Received: 17 January 2021

Accepted: 11 March 2021

Published: 29 March 2021

Publisher's Note: MDPI stays neutral with regard to jurisdictional claims in published maps and institutional affiliations.

Copyright: (c) 2021 by the authors. Licensee MDPI, Basel, Switzerland. This article is an open access article distributed under the terms and conditions of the Creative Commons Attribution (CC BY) license (https:/ / creativecommons.org/licenses/by/ $4.0 /)$.

\begin{abstract}
Cross-links increase the stability of screw-rod systems in biomechanical testing. The aim of this systemic review was to find evidence pertaining to the additional benefit of the implantation of cross-links in clinical practice in regard to different spinal diseases. Therefore, a systematic literature analysis of two online databases was performed according to the PRISMA statement. Inclusion criteria were prospective and retrospective studies investigating the use of cross-links in dorsal instrumentation. Biomechanical studies and case series were excluded. A total of seven retrospective studies remained for final full-text evaluation. In total, two studies each address the use of crosslinks in adolescent idiopathic scoliosis, neuromuscular scoliosis or atlantoaxial fusion, one study in congenital scoliosis. In atlantoaxial fusion the additional use of cross-links may provide earlier bony fusion. In surgical treatment for pediatric scoliosis the additional use of cross-links does not provide additional benefit. Radiological outcome and complication rate did not differ in between groups. No study addressed the use of cross-links in short- or long-segment fusion due to degenerative or traumatic disorders of the spine. There is a deficiency in published literature towards the impact of cross-links in spinal surgery. The current clinical evidence data do not confirm the biomechanical advantages of cross-links in clinical practice. Further studies are needed to warrant the use of cross-links in the future.
\end{abstract}

Keywords: spine; spinal surgery; dorsal instrumentation; spinal fusion; cross-link; stability; systematic review; evidence-based-medicine

\section{Introduction}

Short- and long-segment fusion developed to be a standard procedure in the treatment of various spinal disorders such as scoliosis or degenerative diseases [1-3]. The pedicle screw-rod instrumentation provides good construct stability and is increasingly performed over the last three decades [4,5]. Nevertheless, implant failure, pseudarthrosis, adjacent segment degeneration or loss of curve correction are common complications that cause failed back surgery syndrome and result in poor clinical outcomes [6-8].

In multiple biomechanical studies concerning pedicle screw-rod instrumentation the additional use of cross-links significantly enhanced torsional stiffness and construct rigidity [9-20]. For example, axial segmental stability of human cadaveric spines improved for additional $20 \%$, in a thoracolumbar instability fracture model torsional stiffness increased by $44 \%$ after the additional implantation of cross-links [12,14]. In animal testing, the use of cross-links produced stiffer fusion mass [21]. Since decompression with laminectomy is a standard procedure in spinal surgery but interrupts posterior tension band and increases intervertebral rotation by up to $350 \%$, cross-links are very promising to improve 
the outcome even in short segment fusion [22-24]. As a consequence, cross-links-that were initially developed for surgical treatment of scoliosis-are frequently implanted in all areas of spinal surgery to reduce the rate of complications and maintain correction [5].

However, some biomechanical studies strongly questioned the widespread use of cross-links in everyday clinical practice. According to a cadaver study by Burney et al. the additional implantation of one or two cross-links does not increase rotational stiffness in thoracolumbar 10-level instrumentation [25]. Torsional stiffness was not affected by cross-links in thoracic porcine spines [26]. The question also arises as to whether a crosslink should be used in short- or long segment fusion in the absence of laminectomy and an intact posterior ligamentous complex.

Besides biomechanical investigations, only little is known about the impact of crosslinks in clinical situations. There are no international guidelines or evidence-based recommendations published to direct their use. A retrospective study by Kulkarni et al. even concludes that cross-links may be completely avoidable in most cases of spinal diseases [27]. Additionally, this would safe costs of about USD 1000 to 2000 per cross-link [27,28]. As a consequence, to implant or to not implant cross-links is still a subject of controversy within spinal surgeons.

The aim of this study was to evaluate the clinical impact of cross-links in spinal surgery. Therefore, we systematically reviewed the literature in regard to three main questions:

(1) Does the use of cross-links in dorsal instrumentation affects the radiological outcome, clinical outcome or rate of complication?

(2) Are cross-links necessary in spinal fusion, if laminectomy is not performed?

(3) Overall, does the current state of evidence justify the broad use of cross-links in spinal surgery? Alternatively, in which spinal disorders should cross-links be recommended?

\section{Materials and Methods}

\subsection{Study Design}

We conducted a comprehensive, systematic review of the literature according to the PRISMA statement. Therefore, Cochrane Library and Medline electronic database were searched in March 2020 by using the following search strategy:

(1) Cochrane library [Title Abstract Keyword]: “cross-link OR cross-links OR crosslink OR crosslinks OR <cross link> OR <cross links $>$ OR $<$ transverse connector $>$ OR $<$ transverse connectors $>$ ".

(2) Medline [All text]: “(crosslink OR crosslinks OR cross-link OR cross-links OR crosslinking $\mathrm{OR}<$ cross linking $>$ OR cross-linking $\mathrm{OR}<$ transverse connector $>\mathrm{OR}<$ transverse connectors $>$ OR connector OR connectors OR $<$ rod connector $>$ OR $<$ rod connectors $>$ OR transfixator OR transfixators OR $<$ trans fixations $>$ ) AND (spine OR fusion OR stiffness OR fixation OR stability OR spondylodesis OR instrumentation) AND (randomized OR rct OR $<$ clinical study $>$ OR retrospective OR prospective OR $<$ single center $>$ OR single-center OR multi-center OR multicenter)".

Titles and abstracts were reviewed by two orthopedic spine surgeons in March 2020 independently. Duplicates were removed and full texts were checked for suitability. In addition, bibliographies of included publications were searched for available studies meeting our inclusion criteria. Level of evidence was graded by Oxford Centre of Evidence-Based Medicine (OCEBM, 2011) [29]. Risk of bias was assessed by the Cochrane Collaboration risk-of-bias (RoB) tool [30]. Retrospective studies were graded "high risk".

\subsection{Inclusion and Exclusion Criteria}

Initially, we planned to only include randomized controlled trials (RCT), systematic reviews and meta-analyses that address the use of cross-links in spinal surgery. Since the primary search did not produce any prospective studies, systematic reviews or metaanalyses, we widened our inclusion criteria to comparative cohort and case-control studies. There was no restriction in language. Publications published between January 1980 and 
March 2020 were included. Case series, case reports and biomechanical studies as well as studies that do not compare a cross-link (XL) to a non-crosslink group (NXL) were excluded.

\subsection{Data Collection and Statistical Analysis}

We extracted data concerning study characteristics (author name, year of publication, number of patients, time of follow-up, type of study), study population (number of patients, indication for surgery, sex, age) and postoperative outcome (clinical outcome measured by disease-specific scores, radiological outcome measured by fusion-rate, adjacent segment degeneration, postoperative sagittal or coronal balance and perioperative complications measured by implant failure, superficial and deep wound infection). Patients collectives were assigned to four groups: (i) pediatric scoliosis, (ii) atlantoaxial fusion, (iii) adult shortsegment fusion and (iv) adult long-segment fusion. XL and NXL-groups were compared in terms of the data collected. Descriptive statistics were presented as sample mean, standard deviation/range, absolute and/or relative precision. Overall, $p$-value $<0.05$ was considered statistically significant. Due to lack of publications and heterogeneity of data a meta-analysis was not performed.

\section{Results}

The first search strategy identified 946 studies. After reviewing titles and abstracts, 12 studies remained for full-text assessment. Following inclusion and exclusion criteria, both reviewers identified seven publications that were systematically analyzed [28,31-36]. No publication was questioned. Full-selection process is shown in PRISMA flow diagram by Figure 1.
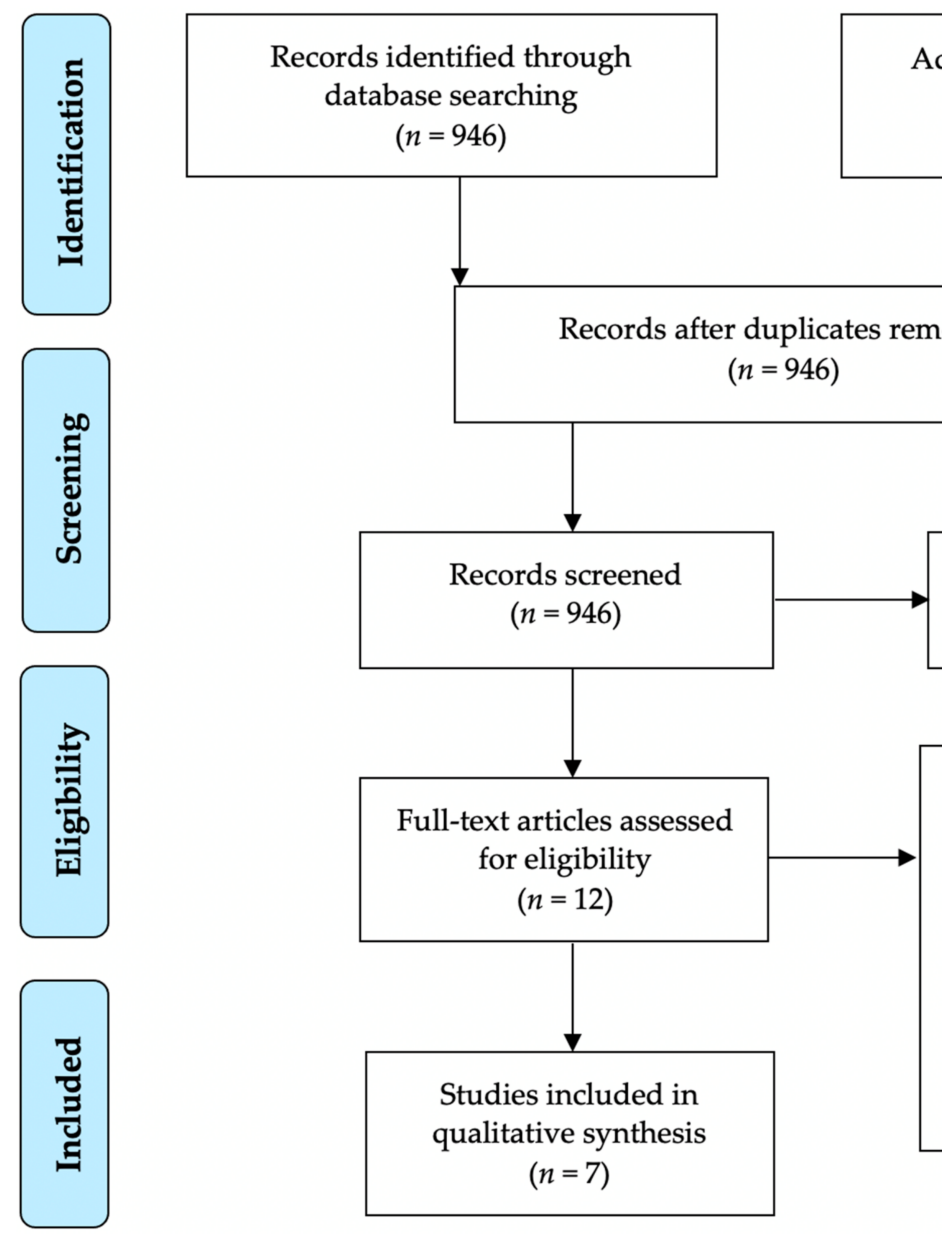

Additional records identified through other sources $(n=0)$ with reasons $(n=5)$

Kim (2005) no control group Asher (2010) no control group

Kulkarni (2013) no control group

Buell (2018) method Lewis (2018) missing data

Figure 1. PRISMA flow diagram. 
Study characteristics and study population are shown in Tables 1 and 2. On average, the included studies consist of 188 patients (min.: 34, max.: 500) with a follow-up time of 6 to 36 months. According to OCEBM there is no level I or level II study. Five studies are level III and two studies level IV evidence. A total of two studies each address the use of cross-links in adolescent idiopathic scoliosis (AIS), neuromuscular scoliosis or posterior atlantoaxial fusion, one study in congenital scoliosis.

Table 1. Study characteristics.

\begin{tabular}{clcccc}
\hline Author (Year) & Study Design & N & $\begin{array}{c}\text { Minimum Follow-up } \\
\text { (Months) }\end{array}$ & Level of Evidence & Risk of Bias \\
\hline Scoliosis & Retrospective & 256 & & III & High \\
Usmani et al. (2019) & Retrospective & 500 & 24 & III & High \\
Garg et al. (2015) & Retrospective & 34 & 24 & III & High \\
Chen et al. (2015) & Retrospective & 100 & 24 & IV & High \\
Garg et al. (2014) & III & High \\
Dhawale et al. (2013) & Retrospective & 75 & 24 & III & High \\
\hline Atlantoaxial Fusion & & & 12 & IV & High \\
Wang et al. (2019) & Retrospective & 317 & 36 & \\
Mizutani et al. (2018) & Retrospective & 35 & &
\end{tabular}

Table 2. Study population.

\begin{tabular}{cccc}
\hline Author (Year) & Number of Patients & Sex & Age (Years) \\
\cline { 2 - 4 } & $\boldsymbol{N}$ (XL/NXL) & Female/Male & Mean ( \pm 1 SD/Range) \\
Scoliosis & & & \\
Usmani et al. (2019) & $256(94 / 162)$ & $123 / 33$ & $14.0( \pm 2.7)$ \\
Garg et al. (2015) & $500(377 / 123)$ & $413 / 83(4$ unknown) & 14.9 \\
Chen et al. (2015) & $34(24 / 19)$ & $14 / 20$ & $3.1(1.8-4.8)$ \\
Garg et al. (2014) & 100 & $38 / 62$ & $13.8(7-21)$ \\
Dhawale et al. (2013) & $75(25 / 50)$ & $61 / 14$ & $14.0( \pm 2.3)$ \\
\hline Atlantoaxial Fusion & & & $38.6(13-74)$ \\
Wang et al. (2019) & $317(149 / 168)$ & $206 / 111$ & $56.1(32-77)$ \\
Mizutani et al. (2018) & $35(18 / 17)$ & $27 / 8$ & \\
\hline
\end{tabular}

\subsection{Scoliosis}

Two different and independent research teams published one article each about the implantation of cross-links in patients with AIS. Garg et al. retrospectively queried a prospectively collected multicenter database of 500 patients with AIS with an average age of 14.9 years [28]. All patients had first time posterior spinal fusion. 413 of the patients were female, $75.4 \%(n=377)$ had cross-links. There was no significant difference in radiographic outcome 24 months after operation. Both groups improved clinically measured by SRS- and SAQ-score. The cross-link group improved significantly in mental health domain of SRS-score. Though, there was no significant difference between the other domains. SAQ-score and the complication rate did not differ significantly. Likewise, Dhawale et al. retrospectively compared 75 patients, who were treated with posterior spinal instrumentation due to AIS with an average age of $14( \pm 2.3)$ years [32]. In total, 61 of the children were female, in $33.3 \%(n=25)$ a cross-link was implanted. Radiological outcome, SRS-score and complication rate did not differ significantly 24 months after surgery. Both studies concluded implantation of cross-links in children with AIS who undergo posterior spinal pedicle screw-based instrumentation does not affect the radiological or clinical long-term outcome. 
Another retrospective study by Garg et al. concentrated on patients with neuromuscular spine deformity, who underwent posterior spinal fusion with pelvic fixation [33]. 100 patients (38 female) with an average age of 13.8 years (min.: 7, max.: 21) were enrolled to the study. Rate of failure of iliac screw fixation was $27 \%$. Distal cross-linking of the pedicle screw construct reduced the rate of iliac screw failure, but bordered on significance (OR, $0.37 ; 95 \%$ CI $0.137-1.007, p=0.052$ ). In the multivariable model only spastic muscle tone predicted iliac screw failure significantly. Patient's baseline data, levels of fusion, implants characteristic or radiologic parameters did not predict failure statistically. Usmani et al. retrospectively queried a prospectively collected multicenter database of 256 patients with cerebral palsy-related neuromuscular scoliosis with an average age of 14.1 years $( \pm 2.7)$ [35]. All patients had first time posterior spinal fusion. In total, 123 of the patients were female, in $36.7 \%(n=94)$ cross-links were implanted. At the 24 months follow-up radiological outcome and complication rate did not differ significantly in between the two groups.

Chen et al. retrospectively analyzed data of 34 patients with congenital scoliosis who underwent posterior hemi vertebrectomy and pedicle screw-based instrumentation in regard to the developmental state of the spinal canal [31]. A total of 20 girls and 14 boys were included. Average age was 37 months (min.: 21, max.: 57), average time of followup was 37 months $( \pm 12)$. Neither pedicle screw instrumentation nor implantation of cross-links affected the development of the spinal canal in a negative way.

\subsection{Atlantoaxial Fusion}

A study by Mitzutani et al. examined the fusion rate 2 years after Goel/Harms procedure for atlantoaxial fixation with $(n=18)$ or without the implantation of cross-links $(n=17)$ [34]. In $86 \%(n=30)$ the indication for surgery was rheumatoid atlantoaxial subluxation. 27 of the patients were female, average age was 56.3 years (min.: 26, max.: 84) in the cross-link group and 53.8 years (min.: 32, max.: 72) in the non-cross-link group. Radiological outcome was measured by fusion rate in CT examination of the cervical spine. The cross-link group yielded significant earlier fusion at the 6-, 12- and 24-months follow-up without significant difference 36 months after surgery.

Wang et al. reported on 317 patients who underwent C1/2 screw-rod reduction fixation and posterior atlantoaxial facet joint release due to atlantoaxial dislocation and basilar invagination (AAD and BI) [36]. Retrospectively, 317 patients were followed-up for at least 12 months with an average age of 38.6 years (min.: 13, max.: 74$) .65 \%(n=206)$ of the patients were female. The cross-links group yielded significant earlier fusion at the 3-, 6- and 12 months follow-up and reached a significant higher JOA score (Japanese Orthopaedic Association) 12 months after surgery.

\subsection{Adult Short-Segment Fusion}

There is no study published that concentrates on implantation of cross-links in adult short-segment fusion.

\subsection{Adult Long-Segment Fusion}

There is no study published that concentrates on implantation of cross-links in adult long-segment fusion.

\section{Discussion}

In this systematic review the clinical impact of cross-links concerning different spinal disorders and types of surgery in regard to radiological and clinical outcome parameters as well as perioperative complications was analyzed. Only seven retrospective studies focused on cross-links comparing a XL- to a NXL-group. No prospective study has been published. Despite the broad use of cross-links, there is only evidence for an additional benefit of cross-links within atlantoaxial fusion. 
Regarding the radiologic outcome, only patients with atlantoaxial fusion due to AAD and BI showed an earlier fusion rate-without significant difference after more than 2 years (Table 3) [34,36]. A total of two studies concerning AIS with an overall sample size of 575 patients did not find significant differences in major radiographic outcomes two years after surgery [28,32]. In addition, cross-links did not yield a significant impact in patients with neuromuscular scoliosis, as neither cross-links affect the major radiographic outcome nor predict implant failure in case of pelvic fixation [33]. However, in children additional implantation of cross-links did not affect the growth of the spinal canal negatively [31].

Table 3. Radiological long-term outcome.

\begin{tabular}{|c|c|c|c|c|}
\hline Author (Year) & $N$ & Treated Disease & Radiological Parameters Assesed & Results \\
\hline \multicolumn{5}{|l|}{ Scoliosis } \\
\hline Usmani et al. (2019) & 256 & $\begin{array}{l}\text { Neuromuscular } \\
\text { scoliosis }\end{array}$ & $\begin{array}{l}\text { Major Cobb angle, pelvic obliquitiy, } \\
\text { thoracal kyphosis, lumbar lordosis }\end{array}$ & $\begin{array}{l}\text { No sign. difference at } 24 \\
\text { months follow-up }\end{array}$ \\
\hline Garg et al. (2015) & 500 & AIS & $\begin{array}{c}\text { Coronal and saggital balance, } \\
\text { shoulder high difference, trunk shift, } \\
\text { coronal plane deformity } \\
\text { measurements (Cobb angle) }\end{array}$ & $\begin{array}{l}\text { Sign. less improvement in } \\
\text { sagittal balance and sign. } \\
\text { greater improvement in } \\
\text { thoracolumbar Cobb angle in } \\
\text { XL-group }\end{array}$ \\
\hline Chen et al. (2015) & 34 & Congenital scoliosis & $\begin{array}{c}\text { Spinal canal parameters } \\
\text { (a.p./transverse), area of the spinal } \\
\text { canal, screw-angle, distance between } \\
\text { bilateral screws }\end{array}$ & $\begin{array}{c}\text { No sign. negative effect on the } \\
\text { develeopement of the spinal } \\
\text { canal }\end{array}$ \\
\hline Garg et al. (2014) & 100 & $\begin{array}{l}\text { Neuromuscular } \\
\text { scoliosis }\end{array}$ & $\begin{array}{l}\text { Levels fused, coronal plane deformity, } \\
\text { pelvic obliquity, distal fixation point, } \\
\text { presence of implant failure/screw } \\
\text { lucency }>2 \mathrm{~mm}\end{array}$ & $\begin{array}{l}\text { No predictor for pelvic fixation } \\
\text { failure }\end{array}$ \\
\hline Dhawale et al. (2013) & 75 & AIS & $\begin{array}{c}\text { Thoracic/lumbar/lateral Cobb angle, } \\
\text { correction rate, apical vertebral } \\
\text { translation/rotation, Risser grade, } \\
\text { Lenke classification }\end{array}$ & $\begin{array}{l}\text { No sign. difference at } 24 \\
\text { months follow-up }\end{array}$ \\
\hline \multicolumn{5}{|l|}{ Atlantoaxial fusion } \\
\hline Wang et al. (2019) & 317 & $\begin{array}{c}\text { Atlantoaxial dislocation } \\
\text { and basilar } \\
\text { invagination }\end{array}$ & $\begin{array}{l}\text { Ant./post. atlantodental interval, } \\
\text { Chamberlain line, cervicomedullary } \\
\text { angle, fusion rate }\end{array}$ & $\begin{array}{l}\text { Sign. higher fusion rate in } \\
\text { XL-group at } 3 / 6 / 12 \text { months } \\
\text { follow-up }\end{array}$ \\
\hline Mizutani et al. (2018) & 35 & $\begin{array}{l}\text { Atlantoaxial } \\
\text { subluxation }\end{array}$ & $\begin{array}{l}\text { Fusion rate-bony union } \mathrm{C} 1 \text { posterior } \\
\text { arch and } \mathrm{C} 2 \text { lamina, ankyosis lateral } \\
\mathrm{C} 1 / 2 \text { joint }\end{array}$ & $\begin{array}{l}\text { Sign. higher fusion rate in } \\
\text { XL-group at } 6 / 12 / 24 \text { months } \\
\text { follow-up without sign. } \\
\text { difference } 3 \text { years after surgery }\end{array}$ \\
\hline
\end{tabular}

AIS: adolescent idiopathic scoliosis; Ant.: Anterior; Post. Posterior; XL Cross-link; Sign.: Significant.

Only three out of the seven studies addressed the clinical outcome, one of them in patients with AAD and BI, two of them in patients with AIS (Table 4) [28,32,36]. Interestingly, patients with AAD and BI and additional implantation of a cross-link achieved a significantly higher neurologic improvement measured by JOA-score 1 year after surgery. Authors conclude this as a consequence of fusion delay and an accompanied psychological burden in the NXL-group, which may lower the corporation for an appropriate rehabilitative therapy [36]. Further, mental health domain of SRS-22r score significantly improved in cross-link groups in one out of two studies regarding the clinical outcome. Anyhow, overall clinical outcome measured by SRS-22r score improved in both studies with respective AIS-without significant difference regarding cross-links used or not [28,32]. 
Table 4. Clinical long-term outcome.

\begin{tabular}{|c|c|c|c|c|}
\hline Author (Year) & $N$ & Treated Disease & $\begin{array}{c}\text { Clinical Parameters } \\
\text { Assessed }\end{array}$ & Results \\
\hline \multicolumn{5}{|l|}{ Scoliosis } \\
\hline Usmani et al. (2019) & 256 & Neuromuscular scoliosis & NA & NA \\
\hline Garg et al. (2015) & 500 & AIS & $\begin{array}{l}\text { SRS-22r score (SRS-score), } \\
\text { SAQ }\end{array}$ & $\begin{array}{l}\text { Sign. improvement in health } \\
\text { domain of SRS-score in XL-group. } \\
\text { No sign. difference in SRS- or } \\
\text { SAQ-score at } 24 \text { months follow-up }\end{array}$ \\
\hline Chen et al. (2015) & 34 & Congenital scoliosis & NA & NA \\
\hline Garg et al. (2014) & 100 & Neuromuscular scoliosis & NA & NA \\
\hline Dhawale et al. (2013) & 75 & AIS & SRS 22r-score & $\begin{array}{l}\text { No sign. difference in SRS-score at } \\
24 \text { months follow-up }\end{array}$ \\
\hline \multicolumn{5}{|l|}{ Atlantoaxial fusion } \\
\hline Wang et al. (2019) & 317 & $\begin{array}{c}\text { Atlantoaxial dislocation and } \\
\text { basilar invagination }\end{array}$ & $\begin{array}{c}\text { Japanese Orthopaedic } \\
\text { Association Score (JOA) }\end{array}$ & $\begin{array}{l}\text { Sign. higher JOA-score in } \\
\text { XL-group at } 12 \text { months follow-up }\end{array}$ \\
\hline Mizutani et al. (2018) & 35 & Atlantoaxial subluxation & NA & NA \\
\hline
\end{tabular}

AIS: Adolescent idiopathic scoliosis; JOA-score: Japanese Orthopedic Association Score; SRS 22r-score: Patient Outcome Questionnaire (Scoliosis Research Society); SAQ-score: Spinal Appearance Questionnaire; XL: Cross-link; Sign.: Significant; NA: Not available.

Across studies, the complication rate did not differ significantly within the two groups (Table 5). There were no significant differences in rate of reoperation or surgical side effects. Therefore, former assumptions of an increased risk of complications associated to the additional implantation of cross-links cannot be confirmed [27]. However, within a retrospective study by Asher et al. different cross-link designs affected the rate of implant corrosion and the development of late operative site pain significantly. Even though there was no control group that had no cross-link, cross-links itself represent a risk factor due to failed back surgery syndrome [37]. In addition, Kim et al. found pseudarthrosis to occur in $69 \%$ at site of implanted cross-links or dominoes in patients with primary fusion due to adult idiopathic scoliosis.

Table 5. Perioperative complications.

\begin{tabular}{|c|c|c|c|c|c|}
\hline \multirow{2}{*}{ Author (Year) } & \multirow{2}{*}{$\mathbf{N}$} & \multirow{2}{*}{ Treated Disease } & \multicolumn{3}{|c|}{ N Complication XL- vs. NXL-Group (\%) } \\
\hline & & & All & Surgical Side Infection & Reoperation \\
\hline \multicolumn{6}{|l|}{ Scoliosis } \\
\hline Usmani et al. (2019) & 256 & Neurom. Scoliosis & $14(16) / 23(14)$ & $11(12) / 13(8)$ & $3(3.2) / 4(2.5)$ \\
\hline Garg et al. (2015) & 500 & AIS & $21(6) / 9(7)$ & $2(0.5) / 0(0)$ & $4(1.1) /(0)$ \\
\hline Chen et al. (2015) & 34 & Congenital scoliosis & NA & NA & NA \\
\hline Garg et al. (2014) & 100 & Neurom. Scoliosis & NA & NA & NA \\
\hline Dhawale et al. (2013) & 75 & AIS & $1(4) / 1(2)$ & $1(4) / 0(0)$ & $1(4) / 1(2)$ \\
\hline \multicolumn{6}{|l|}{ Atlantoaxial Fusion } \\
\hline Wang et al. (2019) & 317 & $\begin{array}{l}\text { Atlantoaxial dislocation and } \\
\text { basilar invagination }\end{array}$ & $7(4.7) / 9(5.4)$ & NA & NA \\
\hline Mizutani et al. (2018) & 35 & Atlantoaxial subluxation & NA & NA & NA \\
\hline
\end{tabular}

AIS: adolescent idiopathic scoliosis; Neurom.: Neuromuscular; XL-group: Cross-link group; NXL-group: Non-cross-link group; NA: not available.

There are no studies published that concentrate on the use of cross-links in short- or long-segment fusion due to degenerative or deformative diseases or that investigate on the 
additional benefit of cross-links in the case of spinal disorders such as infection, tumor or trauma. In a retrospective study Kulkarni et al. reported on 208 patients, who underwent spinal surgery of varied etiology without the implantation of cross-links [27]. Authors concluded that cross-links may be avoidable because none of the cases demonstrated pseudarthroses, implant breakages or rotational instability 1 year after surgery. Only one patient with a thoracolumbar fracture ( $\mathrm{AO}$ type $\mathrm{C}$ ) had radiographic rotational instability after dorsal short-segment fixation, with spontaneous correction after anterior reconstruction. Yet, particularly in cases with high rotational instability cross-links might provide additional benefit in dorsal instrumentation. In biomechanical testing, Chutkan et al. performed facetectomy after posterior mono segmental interbody fusion in calf lumbar spines [11]. As facetectomy increased segmental range of motion, half of the stability in axial rotation was restored due to the additional implantation of a cross-link. Although there is no evidence concerning the use of cross-links in degenerative spine surgery, cross-links might provide additional benefit, particularly in operations with high potential of rotational instability such as segmental fusion with laminectomy or spinal osteotomy. Nevertheless, in spinal degenerative surgery there is a trend towards modern techniques that use minimal-invasive decompression such as laminotomy instead of laminectomy [38]. Advantages are for example higher stability due to preserved facet joints, which may decrease postoperative complications such as adjacent segment degeneration or implant failure [39]. There is no clear regulation neither when in spinal tumor, traumatic or degenerative diseases of the spine to strictly perform laminectomy, nor under which preconditions cross-links provide an additional benefit. The question of whether a cross-link should be inserted through the interspinous ligaments in a pure laminotomy with an intact tension band also remains unanswered. It can be assumed that reasons for the broad use of cross-links in cases of laminectomy are the habit of the surgeon as well as a subjective feeling of increased construct stability.

To summarize our initial questions, cross-links may provide earlier bony union in atlantoaxial instrumentation, whereas within other spinal diseases radiological and clinical outcome did not differ between XL and NXL group. Therefore, a recommendation for the use of cross-links can only be made in case of atlantoaxial instrumentation. No recommendation can be made regarding scoliosis surgery, adult short- and long-segmental dorsal spinal fusion according to the current literature. In addition, no study investigated the use of cross-links in the context of laminectomy. However, cross-links do not seem to increase the risk of perioperative complications. Nevertheless, up to now the current state of evidence does not justify the broad use of cross-links in spinal surgery.

Our systematic review of literature has several limitations. There is no level I or level II study that assessed the use of cross-links in clinical practice. This causes high risk of bias. Second, there are only seven studies to be included in our review which is very little compared with the many different spinal disorders that accompany with different biomechanical requirements and types of operation. A meta-analysis could therefore not be performed. Furthermore, there is no study that investigated on benefits or complications in patients with degenerative spine diseases, even though this might be the largest group within that cross-links are used.

It can be stated that crosslinks are now regularly used throughout spinal surgery. In tumor surgery, traumatology and degenerative surgery. Apart from the atlantoaxial fusion, this happens without adequate evidence. Nowadays, it would certainly be desirable that we investigate the advantages and disadvantages of crosslinks on the basis of a clinical study and thus create an adequate basis for a decision on their use. In long spondylodesis with laminectomy, a crosslink has an obvious function to protect the dura or spinal cord as well as to stabilize it, and a sense of purpose is therefore obvious. Therefore, there is no spasmodic need to evaluate a high degree of evidence in this case [40]. However, in other questions, such as short-distance instrumentation with and without laminectomy, these questions are often intensely debated in clinical departments and should be given a scientific basis. 


\section{Conclusions}

Cross-links were developed to improve torsional stiffness in scoliosis but are widely used within spinal surgery due to different spinal disorders. This is the first study to systematically analyze evidence for the use of cross-links in clinical practice. In surgical treatment for pediatric scoliosis, cross-links did not affect the outcome, in atlantoaxial instrumentation cross-links may provide earlier bony union. Moreover, there is no evidence for the use of crosslinks. This should be investigated and presented in studies for spinal surgery with and without laminectomy.

Author Contributions: Idea and conceptualization, P.E. and J.B.; methodology, T.P. and V.J.H.; investigation/literature search, S.O. and V.J.H.; data curation/data analysis, S.O., T.P. and W.A.W.; writing—original draft preparation, V.J.H.; writing—review and editing, C.M. and M.J.S.; visualization, W.A.W.; supervision, J.B. and P.E. All authors have read and agreed to the published version of the manuscript.

Funding: This research received no external funding.

Institutional Review Board Statement: Not applicable (this article does not contain any studies with human or animal subjects performed by any of the authors).

Informed Consent Statement: Not applicable.

Data Availability Statement: Data are contained within the article. The data presented in this study are available in [28,31-36].

Conflicts of Interest: The authors declare no conflict of interest.

\section{References}

1. Hedlund, R.; Johansson, C.; Hagg, O.; Fritzell, P.; Tullberg, T.; Swedish Lumbar Spine Study Group. The long-term outcome of lumbar fusion in the Swedish lumbar spine study. Spine J. 2016, 16, 579-587. [CrossRef] [PubMed]

2. Hart, R.; Hermsmeyer, J.T.; Sethi, R.K.; Norvell, D.C. Quality and Quantity of Published Studies Evaluating Lumbar Fusion during the Past 10 Years: A Systematic Review. Glob. Spine J. 2015, 5, 207-218. [CrossRef]

3. El-Hawary, R.; Chukwunyerenwa, C. Update on evaluation and treatment of scoliosis. Pediatr. Clin. N. Am. 2014, 61, $1223-1241$. [CrossRef]

4. Rajaee, S.S.; Bae, H.W.; Kanim, L.E.; Delamarter, R.B. Spinal fusion in the United States: Analysis of trends from 1998 to 2008. Spine 2012, 37, 67-76. [CrossRef] [PubMed]

5. Krag, M.H. Biomechanics of thoracolumbar spinal fixation. A review. Spine 1991, 16, S84-S99. [CrossRef] [PubMed]

6. Koller, H.; Pfanz, C.; Meier, O.; Hitzl, W.; Mayer, M.; Bullmann, V.; Schulte, T.L. Factors influencing radiographic and clinical outcomes in adult scoliosis surgery: A study of 448 European patients. Eur. Spine J. 2016, 25, 532-548. [CrossRef] [PubMed]

7. Sebaaly, A.; Lahoud, M.J.; Rizkallah, M.; Kreichati, G.; Kharrat, K. Etiology, evaluation, and treatment of failed back surgery syndrome. Asian Spine J. 2018, 12, 574-585. [CrossRef] [PubMed]

8. How, N.E.; Street, J.T.; Dvorak, M.F.; Fisher, C.G.; Kwon, B.K.; Paquette, S.; Smith, J.S.; Shaffrey, C.I.; Ailon, T. Pseudarthrosis in adult and pediatric spinal deformity surgery: A systematic review of the literature and meta-analysis of incidence, characteristics, and risk factors. Neurosurg. Rev. 2019, 42, 319-336. [CrossRef]

9. Asher, M.; Carson, W.; Heinig, C.; Strippgen, W.; Arendt, M.; Lark, R.; Hartley, M. A modular spinal rod linkage system to provide rotational stability. Spine 1988, 13, 272-277. [CrossRef]

10. Brodke, D.S.; Bachus, K.N.; Mohr, R.A.; Nguyen, B.K. Segmental pedicle screw fixation or cross-links in multilevel lumbar constructs. a biomechanical analysis. Spine J. 2001, 1, 373-379. [CrossRef]

11. Chutkan, N.B.; Zhou, H.; Akins, J.P.; Wenger, K.H. Effects of facetectomy and crosslink augmentation on motion segment flexibility in posterior lumbar interbody fusion. Spine 2008, 33, E828-E835. [CrossRef]

12. Dick, J.C.; Zdeblick, T.A.; Bartel, B.D.; Kunz, D.N. Mechanical evaluation of cross-link designs in rigid pedicle screw systems. Spine 1997, 22, 370-375. [CrossRef] [PubMed]

13. Hart, R.; Hettwer, W.; Liu, Q.; Prem, S. Mechanical stiffness of segmental versus nonsegmental pedicle screw constructs: The effect of cross-links. Spine 2006, 31, E35-E38. [CrossRef] [PubMed]

14. Kuklo, T.R.; Dmitriev, A.E.; Cardoso, M.J.; Lehman, R.A., Jr.; Erickson, M.; Gill, N.W. Biomechanical contribution of transverse connectors to segmental stability following long segment instrumentation with thoracic pedicle screws. Spine 2008, 33, E482-E487. [CrossRef]

15. Lim, T.H.; Eck, J.C.; An, H.S.; Hong, J.H.; Ahn, J.Y.; You, J.W. Biomechanics of transfixation in pedicle screw instrumentation. Spine 1996, 21, 2224-2229. [CrossRef] 
16. Lynn, G.; Mukherjee, D.P.; Kruse, R.N.; Sadasivan, K.K.; Albright, J.A. Mechanical stability of thoracolumbar pedicle screw fixation. The effect of crosslinks. Spine 1997, 22, 1568-1572, discussion 1573. [CrossRef]

17. Pintar, F.A.; Maiman, D.J.; Yoganandan, N.; Droese, K.W.; Hollowell, J.P.; Woodard, E. Rotational stability of a spinal pedicle screw /rod system. J. Spinal Disord. 1995, 8, 49-55. [CrossRef]

18. Lim, T.H.; Kim, J.G.; Fujiwara, A.; Yoon, T.T.; Lee, S.C.; Ha, J.W.; An, H.S. Biomechanical evaluation of diagonal fixation in pedicle screw instrumentation. Spine 2001, 26, 2498-2503. [CrossRef]

19. Wahba, G.M.; Bhatia, N.; Bui, C.N.; Lee, K.H.; Lee, T.Q. Biomechanical evaluation of short-segment posterior instrumentation with and without crosslinks in a human cadaveric unstable thoracolumbar burst fracture model. Spine 2010, 35, 278-285. [CrossRef]

20. Lehman, R.A., Jr.; Dmitriev, A.E.; Wilson, K.W. Biomechanical analysis of the C2 intralaminar fixation technique using a cross-link and offset connector for an unstable atlantoaxial joint. Spine J. 2012, 12, 151-156. [CrossRef]

21. Johnston, C.E., 2nd; Ashman, R.B.; Baird, A.M.; Allard, R.N. Effect of spinal construct stiffness on early fusion mass incorporation. Experimental study. Spine 1990, 15, 908-912. [CrossRef]

22. Zeng, Z.L.; Zhu, R.; Wu, Y.C.; Zuo, W.; Yu, Y.; Wang, J.J.; Cheng, L.M. Effect of Graded Facetectomy on Lumbar Biomechanics. J. Healthc Eng. 2017, 2017, 7981513. [CrossRef]

23. Zander, T.; Rohlmann, A.; Klockner, C.; Bergmann, G. Influence of graded facetectomy and laminectomy on spinal biomechanics. Eur. Spine J. 2003, 12, 427-434. [CrossRef]

24. Overdevest, G.; Vleggeert-Lankamp, C.; Jacobs, W.; Thome, C.; Gunzburg, R.; Peul, W. Effectiveness of posterior decompression techniques compared with conventional laminectomy for lumbar stenosis. Eur. Spine J. 2015, 24, 2244-2263. [CrossRef]

25. Burney, M.U.; Mukherjee, D.P.; Ogden, A.L.; Robinson, E.; McCall, R.E. A biomechanical study of posterior spinal instrumentation using pedicle screws with and without cross-links. J. Spinal Disord. Tech. 2005, 18, 364-368. [CrossRef]

26. Valdevit, A.; Kambic, H.E.; McLain, R.F. Torsional stability of cross-link configurations: A biomechanical analysis. Spine J. 2005, 5, 441-445. [CrossRef]

27. Kulkarni, A.G.; Dhruv, A.N.; Bassi, A.J. Should we cross the cross-links? Spine 2013, 38, E1128-E1134. [CrossRef]

28. Garg, S.; Niswander, C.; Pan, Z.; Erickson, M. Cross-links do not improve clinical or radiographic outcomes of posterior spinal fusion with pedicle screws in adolescent idiopathic scoliosis: A multicenter cohort study. Spine Deform. 2015, 3, 338-344. [CrossRef] [PubMed]

29. Howick, J.; Chalmers, I.; Glasziou, P.; Greenhalgh, T.; Heneghan, C.; Liberati, A.; Moschetti, I.; Phillips, B.; Thornton, H.; Goddard, O.; et al. The Oxford Levels of Evidence 2. Oxford Centre for Evidence-Based Medicine. Available online: https: //www.cebm.net/index.aspx?o=5653 (accessed on 13 November 2020).

30. Higgins, J.P.; Altman, D.G.; Gotzsche, P.C.; Juni, P.; Moher, D.; Oxman, A.D.; Savovic, J.; Schulz, K.F.; Weeks, L.; Sterne, J.A.; et al. The Cochrane Collaboration's tool for assessing risk of bias in randomised trials. BMJ 2011, 343, d5928. [CrossRef]

31. Chen, Z.H.; Chen, X.; Zhu, Z.Z.; Wang, B.; Qian, B.P.; Zhu, F.; Sun, X.; Qiu, Y. Does addition of crosslink to pedicle-screw-based instrumentation impact the development of the spinal canal in children younger than 5 years of age? Eur. Spine J. 2015, 24, 1391-1398 [CrossRef]

32. Dhawale, A.A.; Shah, S.A.; Yorgova, P.; Neiss, G.; Layer, D.J., Jr.; Rogers, K.J.; Gabos, P.G.; Holmes, L., Jr. Effectiveness of cross-linking posterior segmental instrumentation in adolescent idiopathic scoliosis: A 2-year follow-up comparative study. Spine J. 2013, 13, 1485-1492. [CrossRef]

33. Garg, S.; Holland, C.; LaGreca, J.; McNair, B.; Erickson, M. Predicting failure of iliac fixation in neuromuscular spine deformity. Spine Deform. 2014, 2, 214-218. [CrossRef] [PubMed]

34. Mizutani, J.; Inada, A.; Kato, K.; Kondo, A.; Kainuma, S.; Fujita, K.; Yagi, K.; Shimamura, Y.; Fukuoka, M.; Shibamoto, Y.; et al. Advantages of an on-the-screwhead crosslink connector for atlantoaxial fixation using the Goel/Harms technique J. Clin. Neurosci. 2018, 50, 183-189. [CrossRef]

35. Usmani, M.F.; Shah, S.A.; Yaszay, B.; Samdani, A.F.; Cahill, P.J.; Newton, P.O.; Marks, M.C.; Sponseller, P.D. The role of cross-links in posterior spinal fusion for cerebral palsy-related scoliosis. Spine 2019, 44, E1256-E1263. [CrossRef] [PubMed]

36. Wang, H.W.; Yin, Y.H.; Li, T.; Yu, X.G.; Qiao, G.Y. Effects of transverse connector on reduction and fixation of atlantoaxial dislocation and basilar invagination using posterior C1-C2 screw-rod technique. Spine J. 2019, 19, 1995-2002. [CrossRef] [PubMed]

37. Asher, M.A.; Lai, S.M.; Burton, D.C. Analysis of instrumentation/fusion survivorship without reoperation after primary posterior multiple anchor instrumentation and arthrodesis for idiopathic scoliosis. Spine J. 2010, 10, 5-15. [CrossRef]

38. Wipplinger, C.; Melcher, C.; Hernandez, R.N.; Lener, S.; Navarro-Ramirez, R.; Kirnaz, S.; Schmidt, F.A.; Kim, E.; Hartl, R. “One and a half" minimally invasive transforaminal lumbar interbody fusion: Single level transforaminal lumbar interbody fusion with adjacent segment unilateral laminotomy for bilateral decompression for spondylolisthesis with bisegmental stenosis. J. Spine Surg. 2018, 4, 780-786. [CrossRef] [PubMed]

39. Grunert, P.; Reyes, P.M.; Newcomb, A.G.; Towne, S.B.; Kelly, B.P.; Theodore, N.; Hartl, R. Biomechanical Evaluation of Lumbar Decompression Adjacent to Instrumented Segments. Neurosurgery 2016, 79, 895-904. [CrossRef] [PubMed]

40. Smith, G.C.; Pell, J.P. Parachute use to prevent death and major trauma related to gravitational challenge: Systematic review of randomised controlled trials. BMJ 2003, 327, 1459-1461. [CrossRef] 